\title{
Current Practice of Airway Stenting in the Adult Population in Europe: A Survey of the European Association of Bronchology and Interventional Pulmonology (EABIP)
}

\author{
Hervé Dutau ${ }^{1}$ David Breen ${ }^{2}$ Antonio Bugalho ${ }^{3}$ Levent Dalar ${ }^{4}$ Johannes Daniels ${ }^{5}$ \\ Christophe Dooms $^{6}$ Ralf Eberhardt ${ }^{7}$ Lars Ek $^{8}$ Milena Encheva ${ }^{9}$ Michel Febvre ${ }^{10}$ \\ Martin Hackl ${ }^{11}$ Sirje Marran ${ }^{12}$ Zsolt Papai-Szekely ${ }^{13}$ Michael Perch ${ }^{14}$ Mihovil Roglic ${ }^{15}$ \\ Antoni Rosell ${ }^{16}$ Ales Rozman ${ }^{17}$ Pallav L. Shah ${ }^{18}$ Marioara Simon ${ }^{19}$ Artur Szlubowski ${ }^{20}$ \\ Grigoris Stratakos ${ }^{21}$ Arve Sundset ${ }^{22}$ Toomas Uibu ${ }^{23}$ Christophe Von Garnier ${ }^{24}$ \\ Bojan Zaric ${ }^{25}$ Marija Zdraveska ${ }^{26}$ Lina Zuccatosta ${ }^{27}$ Darijo Bokan ${ }^{28}$ Syed Arshad Husain 29 \\ Semra Bilaceroglu ${ }^{30}$ Paola Gasche-Soccal ${ }^{31}$ Stefano Gasparini ${ }^{27}$ Felix J.F. Herth ${ }^{7}$ \\ Muhammed Munavvar 32
}

\begin{abstract}
${ }^{1}$ Department of Thoracic Oncology, Pleural Diseases and Interventional Pulmonology, North Hospital of Marseille, Aix-Marseille University, Marseille, France; ${ }^{2}$ Interventional Respiratory Unit, Department of Respiratory Medicine, Galway University Hospitals, Galway, Ireland; ${ }^{3}$ Pulmonology Department, CUF Infante Santo Hospital and CUF Descobertas Hospital, and Chronic Diseases Research Center, NOVA Medical School, Lisbon, Portugal; ${ }^{4}$ Department of Pulmonary Medicine, School of Medicine, Istanbul Bilim University, Istanbul, Turkey; ${ }^{5}$ Department of Pulmonary Diseases, VU University Medical Center, Amsterdam, The Netherlands; ${ }^{6}$ Department of Respiratory Diseases, University Hospitals KU Leuven, on behalf of the Thoracic Endoscopy Working Group of the Belgian Society for Pulmonology, Leuven, Belgium; ${ }^{7}$ Department of Pulmonology and Critical Care Medicine, Thoraxklinik, University of Heidelberg and Translational Lung Research Center Heidelberg (TLRCH), German Center for Lung Research (DZL), Heidelberg, Germany; ${ }^{8}$ Department of Heart and Lung Diseases, Skåne University Hospital, Lund, Sweden; ${ }^{9}$ Clinic of Pulmonary Diseases, Military Medical Academy, Sofia, Bulgaria; ${ }^{10}$ Pulmonology Department, Hôpital Tenon, AP-HP, Paris, France; ${ }^{11}$ Department of Pulmonology, Landeskrankenhaus - Universitätskliniken Innsbruck, Innsbruck, Austria; ${ }^{12}$ Department of Endoscopy, North Estonia Medical Centre, Tallinn, Estonia; ${ }^{13}$ Fejér Megyei Szent György Kórház, Székesfehérvár, Hungary; ${ }^{14}$ Department of Cardiology, Section for Lung Transplantation and Respiratory Medicine, Rigshospitalet, University of Copenhagen, Copenhagen, Denmark; ${ }^{15}$ Department for Lung Diseases Jordanovac, University Hospital Centre Zagreb, Zagreb, Croatia; ${ }^{16}$ Servei de Pneumologia, Hospital Universitari de Bellvitge, Idibell, Ciberes, Universitat de Barcelona, Barcelona, Spain; ${ }^{17}$ Department of Respiratory Endoscopy/Interventional Pulmonology, University Clinic Golnik, Golnik, Slovenia; ${ }^{18}$ Royal Brompton \& Harefield NHS Foundation Trust, and Imperial College, London, UK; ${ }^{19}$ Bronchoscopy Department, Pulmonology Clinic, Cluj-Napoca, Romania; ${ }^{20}$ Endoscopy Unit, John Paul II Hospital, Krakow, Poland; ${ }^{21}$ Interventional Pulmonology Unit, 1st Respiratory Medicine Department, National and Kapodistrian University of Athens, Sotiria Hospital, Athens, Greece; ${ }^{22}$ Department of Respiratory Medicine, Oslo University Hospital, Rikshospitalet, Oslo, Norway; ${ }^{23}$ Department of Respiratory Diseases, Tampere University Hospital, Tampere, Finland; ${ }^{24}$ Respiratory Medicine, Inselspital, University of Bern, Bern, Switzerland; ${ }^{25}$ Institute for Pulmonary Diseases of Vojvodina, Clinic for Thoracic Oncology, University of Novi Sad, Faculty of Medicine, Sremska Kamenica, Serbia; ${ }^{26} \mathrm{PHI}$ University Clinic of Pulmology and Allergy, Skopje, Macedonia; ${ }^{27}$ Pulmonary Diseases Unit, Azienda Ospedali Riuniti, Ancona, Italy; ${ }^{28}$ Institute for Pulmonary Diseases of Vojvodina, Clinical Trials Unit, Sremska Kamenica, Serbia; ${ }^{29}$ Maidstone Hospital, Maidstone, UK; ${ }^{30}$ Department of Pulmonary Medicine, Izmir D, Suat Seren Training and Research Hospital for Thoracic Medicine and Surgery, Izmir, Turkey; ${ }^{31}$ Service of Pulmonary Medicine, Geneva University Hospitals, Geneva, Switzerland; ${ }^{32}$ Department of Respiratory Medicine, Royal Preston Hospital, Preston, UK
\end{abstract}

H.D., S.A.H., S.B., P.G.-S., S.G., F.J.F.H., M.M.: EABIP Executive Committee 2014-2016.

D.B., A.B., L.D., J.D., C.D., R.E., L.E., M.E. M.F., M.H., S.M., Z.P.-S., M.P., M.R., A. Rosell, A. Rozman, P.L.S., M.S., A. Szlubowski, G.S., A. Sundset, T.U., C.G., B.Z., M.Z., L.Z.: EABIP Board of National Delegates.

KARGER

(c) 2017 S. Karger AG, Basel

E-Mail karger@karger.com

www.karger.com/res
Dr. Hervé Dutau

Department of Thoracic Oncology, Pleural Diseases and Interventional Pulmonology Hôpital Nord, Chemin des Bourrely

FR-13915 Marseille 20 (France)

E-Mail hdutau@ap-hm.fr 


\section{Keywords}

Interventional pulmonology · Interventional bronchoscopy . Airway stenting · Rigid bronchoscopy · Flexible

bronchoscopy · Survey

\section{Abstract}

Background: Airway stenting (AS) commenced in Europe circa 1987 with the first placement of a dedicated silicone airway stent. Subsequently, over the last 3 decades, AS was spread throughout Europe, using different insertion techniques and different types of stents. Objectives: This study is an international survey conducted by the European Association of Bronchology and Interventional Pulmonology (EABIP) focusing on AS practice within 26 European countries. Methods: A questionnaire was sent to all EABIP National Delegates in February 2015. National delegates were responsible for obtaining precise and objective data regarding the current AS practice in their country. The deadline for data collection was February 2016. Results: France, Germany, and the UK are the 3 leading countries in terms of number of centres performing AS. These 3 nations represent the highest ranked nations within Europe in terms of gross national income. Overall, pulmonologists perform AS exclusively in 5 countries and predominately in 12 . AS is performed almost exclusively in public hospitals. AS performed under general anaesthesia is the rule for the majority of institutions, and local anaesthesia is an alternative in 9 countries. Rigid bronchoscopy techniques are predominant in 20 countries. Amongst commercially available stents, both Dumon and Ultraflex are by far the most commonly deployed. Finally, 11 countries reported that AS is an economically viable activity, while 10 claimed that it is not. Conclusion: This EABIP survey demonstrates that there is significant heterogeneity in AS practice within Europe. Therapeutic bronchoscopy training and economic issues/reimbursement for procedures are likely to be the primary reasons explaining these findings.

(c) 2017 S. Karger AG, Basel

\section{Introduction}

The main purpose of airway stenting (AS) is to restore and maintain luminal patency. Any endoluminal or extrinsic pathology causing more than $50 \%$ reduction in the size of the airway lumen can lead to debilitating symptoms such as dyspnoea. These symptoms can be significantly improved by the placement of an airway stent [1, 2]. Although many attempts were made to stent the cen- tral airway in the past [3-14], it was not until the late twentieth century that the commercial era of AS commenced in Europe. A French doctor, Jean Francois Dumon, was the first physician to place a dedicated and specially designed airway silicone stent in 1987 [15]. Subsequently, several companies developed other airway stents using silicone or metallic components. In the last 30 years, numerous reports have been published describing the placement of self-expanding and balloon-expandable metal stents for the treatment of central airway diseases [16-33]. However, despite the availability of additional commercial products on the market, the Dumon stent (Tracheobronxane ${ }^{\circledR}$; Novatech, La Ciotat, France) has remained the most commonly placed stent worldwide and the "gold standard" for the treatment of both benign and malignant airway stenoses over the last 20 years [1, 2]. These stents have 2 specific designs: straight and $\mathrm{Y}$ shaped (for disease involving the carina) [34]. Silicone stent placement requires a skill set in rigid bronchoscopy (RB), while metallic stent placement can be performed using flexible bronchoscopes.

The European Association of Bronchology and Interventional Pulmonology (EABIP) was founded in 2002 with the objective to exchange knowledge and experience amongst interventional pulmonologists within Europe. This has been achieved through joint international multicentre research projects, establishing procedural and training standards, and agreeing on a unified terminology to improve communication within the community of European interventional pulmonologists. A European survey was launched through the EABIP executive board to investigate AS practice in the 26 European countries represented by an EABIP national delegate.

\section{Materials and Methods}

A questionnaire was developed by the EABIP board members and sent to all EABIP national delegates representing 26 European countries (Appendix 1). Each national delegate was responsible for obtaining the most precise and objective data regarding AS practice in his/her country.

Statistical analysis of the data was performed using the software package IBM SPSS Statistics 20 (Statistical Package for the Social Sciences). Continuous parameters are presented by means when normally distributed or medians and standard deviations or range. Categorical variables are reported as frequencies and percentages. Univariate analysis involved the use of analysis of variance (ANOVA) for multiple continuous variables. For the analysis of correlation, the Pearson correlation test was used for continuous data and the Spearman test for categorical data. Values were considered statistically significant for a level of $p<0.05$. 
Fig. 1. Number of centers performing airway stenting in 26 European countries.

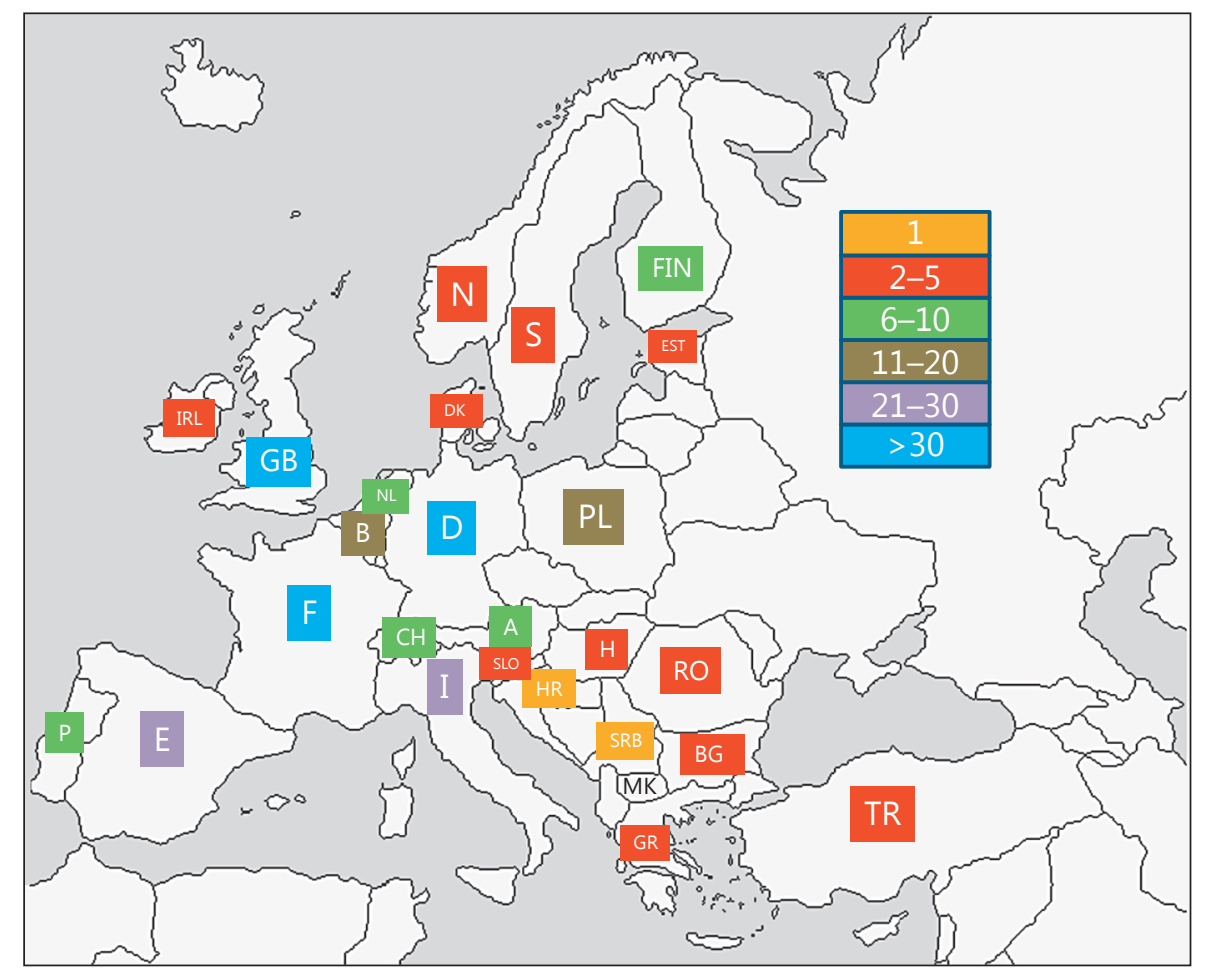

\section{Results}

All 26 European national delegates responded to the questionnaire. AS (Fig. 1) is performed in more than 30 centres in 3 countries (France, Germany, and the UK), in 21-30 centres in 2 countries (Italy and Spain), in 11-20 centres in 2 countries (Belgium and Poland), in 6-10 centres in 5 countries (Austria, Finland, The Netherlands, Portugal, and Switzerland), in 2-5 centres in 11 countries (Bulgaria, Denmark, Estonia, Greece, Hungary, Ireland, Norway, Romania, Slovenia, Sweden, and Turkey), and in a single centre in 2 countries (Croatia and Serbia). In addition, since the close of the survey in February 2016, two additional centres have started performing AS in Serbia. Finally, 1 national delegate reported that AS was not performed (Macedonia).

With regard to specialties performing AS, delegates reported that it is exclusively performed (Table 1) by pulmonologists in 5 countries (Croatia, The Netherlands, Portugal, Romania, and Serbia) and predominately by pulmonologists in 12 countries (Austria, Belgium, Bulgaria, France, Germany, Greece, Hungary, Ireland, Norway, Sweden, Switzerland, and Turkey). A further 3 delegates reported that AS is mainly performed by thoracic surgeons (Estonia, Finland, and Poland). Finally, AS is equal- ly performed by pulmonologists and thoracic surgeons in 4 countries (Italy, Slovenia, Spain, and the UK), and equally performed by thoracic surgeons and ears, nose, and throat (ENT) surgeons in 1 country only (Denmark). In total, ENT surgeons perform AS in 14 countries (Belgium, Bulgaria, Denmark, Finland, France, Germany, Greece, Hungary, Italy, Norway, Poland, Sweden, Switzerland, and the UK). In addition, radiologists perform AS in 4 countries (France, Hungary, Spain, and the UK).

In all countries, AS is predominately performed within the public hospital sector. In only 10 of the 26 countries (Table 1), AS is performed in private hospitals.

General anaesthesia (GA) is almost the exclusive mode of anaesthesia in the majority of countries; indeed, 16 nations reported that the use of GA is exclusive. However, within the UK system, both GA and local anaesthesia are equally utilized. Stents are placed under local anaesthesia in 9 countries (Table 1 ).

$\mathrm{RB}$ is the main technique for AS in 20 countries (Table 1). Among these 20 countries, $\mathrm{RB}$ is the exclusive technique in 5 countries (Croatia, Hungary, Italy, Romania, and Slovenia), and 3 countries reported that RB and flexible bronchoscopy (FB) are equally performed (Denmark, Switzerland, and the UK). Conversely, FB is the favoured technique in 2 countries (Finland and Norway). 
Table 1. Summary of national delegates' answers to the questionnaire

\begin{tabular}{|c|c|c|c|c|c|c|c|c|c|}
\hline & $\begin{array}{l}\text { Population, } \\
\text { millions } \\
\text { (rank) }\end{array}$ & $\begin{array}{l}\text { GNI, billion } \\
\text { dollars (rank) }\end{array}$ & $\begin{array}{l}\text { PCI, dollars } \\
\text { (rank) }\end{array}$ & $\begin{array}{l}\text { Centres, } \\
n\end{array}$ & Who & Where & LA/GA & $\mathrm{FB} / \mathrm{RB}$ & $\begin{array}{l}\text { Economically } \\
\text { valuable }\end{array}$ \\
\hline Belgium & $11(10)$ & $422(9)$ & $40,357(6)$ & $11-20$ & Pul $>$ ENT & Pub & $\mathrm{GA}>\mathrm{LA}$ & $\mathrm{RB}>\mathrm{FB}$ & yes \\
\hline Bulgaria & $8(15)$ & $105(21)$ & $15,105(22)$ & $2-5$ & Pul $>$ TS $=$ ENT & Pub $>$ Pri & GA & $\mathrm{RB}>\mathrm{FB}$ & no \\
\hline Croatia & $4.5(22)$ & $79(23)$ & $17,649(21)$ & 1 & Pul & Pub & GA & $\mathrm{RB}$ & no \\
\hline Finland & $5.3(19)$ & $195(19)$ & $37,105(11)$ & $6-10$ & $\mathrm{TS}>\mathrm{ENT}>\mathrm{Pul}$ & Pub & $\mathrm{GA}>\mathrm{LA}$ & $\mathrm{FB}>\mathrm{RB}$ & yes \\
\hline France & $66(3)$ & $2,273(3)$ & $34,305(12)$ & $>30$ & $\mathrm{Pul}>\mathrm{TS}=\mathrm{ENT}=\mathrm{Rad}$ & Pub $>$ Pri & GA & $\mathrm{RB}>\mathrm{FB}$ & yes \\
\hline Germany & $81(1)$ & $3,227(1)$ & $39,841(7)$ & $>30$ & Pul $>$ TS $=$ ENT & Pub & $\mathrm{GA}>\mathrm{LA}$ & $\mathrm{RB}>\mathrm{FB}$ & yes \\
\hline Greece & $11(10)$ & $267(15)$ & $24,788(16)$ & $2-5$ & $\mathrm{Pul}>\mathrm{TS}=\mathrm{ENT}$ & Pub $>$ Pri & $\mathrm{GA}>\mathrm{LA}$ & $\mathrm{RB}>\mathrm{FB}$ & no \\
\hline Hungary & $9.8(13)$ & $197(18)$ & $19,820(20)$ & $2-5$ & Pul $>$ TS $=\mathrm{ENT}=\mathrm{Rad}$ & Pub & GA & $\mathrm{RB}$ & no \\
\hline Norway & $5(20)$ & $282(13)$ & $54,820(1)$ & $2-5$ & Pul $>$ ENT & Pub & GA & $\mathrm{FB}>\mathrm{RB}$ & no \\
\hline Poland & $38.3(7)$ & $814(7)$ & 21,228 (19) & $11-20$ & $\mathrm{TS}>\mathrm{Pul}=\mathrm{ENT}$ & Pub & GA & $\mathrm{RB}>\mathrm{FB}$ & $\mathrm{MD}$ \\
\hline Portugal & $10.5(12)$ & $243(16)$ & $22,500(18)$ & $6-10$ & Pul & Pub $>$ Pri & GA & $\mathrm{RB}>\mathrm{FB}$ & no \\
\hline Romania & $20(8)$ & $281(14)$ & $13,000(23)$ & $2-5$ & Pul & Pub & GA & $\mathrm{RB}$ & no \\
\hline Serbia & $8(15)$ & $80(22)$ & $11,161(24)$ & 1 & Pul & Pub & GA & $\mathrm{RB}+\mathrm{FB}$ & no \\
\hline Slovenia & $2(24)$ & $56(24)$ & $28,416(15)$ & $2-5$ & Pul=TS & Pub & GA & $\mathrm{RB}$ & yes \\
\hline Spain & $48(6)$ & $1,389(5)$ & $29,096(14)$ & $21-30$ & $\mathrm{Pul}=\mathrm{TC}>\mathrm{Rad}$ & Pub $>$ Pri & GA & $\mathrm{RB}>\mathrm{FB}$ & no \\
\hline Sweden & $9.5(14)$ & $394(10)$ & $40,499(5)$ & $2-5$ & Pul $>$ ENT & Pub & $\mathrm{GA}>\mathrm{LA}$ & $\mathrm{RB}>\mathrm{FB}$ & yes \\
\hline Switzerland & $8(15)$ & $370(11)$ & $45,934(2)$ & $6-10$ & Pul $>>$ ENT & Pub $>$ Pri & $\mathrm{GA}>\mathrm{LA}$ & $\mathrm{RB}=\mathrm{FB}$ & yes \\
\hline Turkey & $75(2)$ & $822(6)$ & $10,184(26)$ & $2-5$ & Pul>TS & Pub $>$ Pri & GA & $\mathrm{RB}>\mathrm{FB}$ & yes \\
\hline UK & $63.7(4)$ & $2,378(2)$ & $37,306(10)$ & $>30$ & $\mathrm{Pul}=\mathrm{TS}>\mathrm{Rad}=\mathrm{ENT}$ & Pub $>$ Pri & $\mathrm{GA}=\mathrm{LA}$ & $\mathrm{FB}=\mathrm{RB}$ & $\mathrm{MD}$ \\
\hline
\end{tabular}

GNI, global net income; PCI, per capita income; Pul, pulmonologists; TS, thoracic surgeons; ENT, ears, nose, and throat surgeons; Rad, radiologists; Pub, public centre; Pri, private centre; GA, general anaesthesia; LA, local anaesthesia; RB, rigid bronchoscopy; FB, flexible bronchoscopy.

Table 2 demonstrates the commercially available stents on the market in each country. Overall, the Dumon straight and Y-shaped stents, Polyflex, T-Tube, Ultraflex, Dynamic, and Silmet stents are the most widely available stents. Delegates from 8 countries reported that there were more than 10 commercially available brands available on the market in their country (Austria, France, Germany, The Netherlands, Spain, Sweden, and Turkey). On the other hand, 2 countries have less than 5 commercially available stents available (Norway and Serbia).

Amongst the commercially available stents (Table 2), the Dumon and the Ultraflex stents are by far the most commonly placed stents. The Dumon and Ultraflex stents are almost equally popular - the Dumon stent is ranked within the top 3 stents in 18 countries; while this position belongs to the Ultraflex in 15 countries. After these 2 leading stents, third place is occupied by the Aerstent, which is in the top 3 rankings in 4 countries and the number 1 placed stent in 3 countries. Finally, 5 countries reported that centres also place Silmet and Microtech stents.

In total, 12 countries reported that AS is an economically viable activity, while 10 countries claimed that it is not financially rewarding for their health system (Table 1).

Table 3 reports the data on global net incomes and per capita income per country. This demonstrates that countries with a total number of AS centres between 11 and 20 have the highest average global net income. Countries with $6-10$ centres have the highest average per capita income. There is a statistically significant association between the number of centres and the average global net income of that nation $(\mathrm{F}=3,453, p=0.018)$. In addition, there is a strong statistical correlation between the number of centres per nation and its overall ranking on the 
Table 2. Commercially available stents and the 3 most placed stents per country

\begin{tabular}{|c|c|c|c|c|c|c|c|c|c|c|c|c|c|c|c|c|}
\hline & \multicolumn{6}{|c|}{ Silicone stents } & \multirow{2}{*}{$\frac{\text { Hybrid stents }}{\text { Dynamic Y }}$} & \multicolumn{7}{|c|}{ Metallic stents } & \multirow[t]{2}{*}{ Others } & \multirow[t]{2}{*}{ Total } \\
\hline & Dumon & $\begin{array}{l}\text { Poly- } \\
\text { flex }\end{array}$ & $\begin{array}{l}\text { Nop- } \\
\text { pen }\end{array}$ & Hood & $\begin{array}{l}\text { T- } \\
\text { Tube }\end{array}$ & $\begin{array}{l}\text { Dumon } \\
\mathrm{Y}\end{array}$ & & $\begin{array}{l}\text { Ultra- } \\
\text { flex }\end{array}$ & Aero & $\begin{array}{l}\text { Micro- } \\
\text { Tech }\end{array}$ & $\begin{array}{l}\text { Aer- } \\
\text { stent }\end{array}$ & $\begin{array}{l}\text { Ha- } \\
\text { naro }\end{array}$ & Silmet & $\mathrm{NiTi}$ & & \\
\hline Austria & 2 & $\mathrm{x}$ & & & $\mathrm{x}$ & $\mathrm{x}$ & 3 & $\mathrm{x}$ & $\mathrm{x}$ & $\mathrm{x}$ & 1 & $\mathrm{x}$ & & $\mathrm{x}$ & & 11 \\
\hline Belgium & 1 & $\mathrm{x}$ & $\mathrm{x}$ & & $\mathrm{x}$ & $\mathrm{x}$ & $\mathrm{x}$ & 2 & & 3 & & & $\mathrm{x}$ & & & 9 \\
\hline Bulgaria & 1 & $\mathrm{x}$ & & & 2 & $\mathrm{x}$ & $\mathrm{x}$ & $\mathrm{x}$ & & 3 & & & & & & 7 \\
\hline Croatia & 1 & $\mathrm{x}$ & & & & $\mathrm{x}$ & $\mathrm{x}$ & $\mathrm{x}$ & & & 3 & $\mathrm{x}$ & & & Egis (2) & 8 \\
\hline Denmark & $\mathrm{x}$ & & & $\mathrm{x}$ & $\mathrm{x}$ & $\mathrm{x}$ & $\mathrm{x}$ & $\mathrm{x}$ & $\mathrm{x}$ & $\mathrm{x}$ & $\mathrm{x}$ & & & & & 9 \\
\hline Estonia & 3 & 1 & & & $\mathrm{x}$ & $\mathrm{x}$ & $\mathrm{x}$ & $\mathrm{x}$ & & 2 & & & & & Egis & 8 \\
\hline Finland & $\mathrm{x}$ & $\mathrm{x}$ & & & $\mathrm{x}$ & $\mathrm{x}$ & $\mathrm{x}$ & 1 & & $\mathrm{x}$ & & & $\mathrm{x}$ & 2 & & 9 \\
\hline France & 1 & $\mathrm{x}$ & & $\mathrm{x}$ & $\mathrm{x}$ & $\mathrm{x}$ & $\mathrm{x}$ & 3 & $\mathrm{x}$ & $\mathrm{x}$ & $\mathrm{x}$ & $\mathrm{x}$ & 2 & $\mathrm{x}$ & & 13 \\
\hline Germany & 1 & $\mathrm{x}$ & $\mathrm{x}$ & & $\mathrm{x}$ & $\mathrm{x}$ & $\mathrm{x}$ & 2 & & $\mathrm{x}$ & $\mathrm{x}$ & $\mathrm{x}$ & $\mathrm{x}$ & $\mathrm{x}$ & & 13 \\
\hline Greece & 1 & $\mathrm{x}$ & & & $\mathrm{x}$ & $\mathrm{x}$ & & $\mathrm{x}$ & 3 & $\mathrm{x}$ & & & 2 & & & 8 \\
\hline Hungary & 1 & & & & & $\mathrm{x}$ & 3 & $\mathrm{x}$ & & & & & 2 & $\mathrm{x}$ & & 6 \\
\hline Ireland & 2 & $\mathrm{x}$ & & & & $\mathrm{x}$ & & 1 & $\mathrm{x}$ & & & & $\mathrm{x}$ & 3 & & 7 \\
\hline Italy & 1 & $\mathrm{x}$ & & & $\mathrm{x}$ & $\mathrm{x}$ & $\mathrm{x}$ & 2 & & & & & 3 & & & 7 \\
\hline The Netherlands & 2 & $\mathrm{x}$ & $\mathrm{x}$ & & $\mathrm{x}$ & $\mathrm{x}$ & $\mathrm{x}$ & 3 & $\mathrm{x}$ & $\mathrm{x}$ & 1 & $\mathrm{x}$ & $\mathrm{x}$ & & & 12 \\
\hline Norway & 3 & & & 2 & $\mathrm{x}$ & & & 1 & & & & & & & & 4 \\
\hline Poland & $\mathrm{x}$ & $\mathrm{x}$ & & & $\mathrm{x}$ & $\mathrm{x}$ & $\mathrm{x}$ & $\mathrm{x}$ & & $\mathrm{x}$ & & & $\mathrm{x}$ & & & 8 \\
\hline Portugal & 2 & $\mathrm{x}$ & & 1 & $\mathrm{x}$ & $\mathrm{x}$ & & 3 & & & & $\mathrm{x}$ & $\mathrm{x}$ & & & 8 \\
\hline Romania & 1 & $\mathrm{x}$ & & & $\mathrm{x}$ & $\mathrm{x}$ & & 2 & & & & & 3 & & Enbio & 6 \\
\hline Serbia & & 2 & & & $\mathrm{x}$ & & 3 & 1 & & & & & & & & 4 \\
\hline Slovenia & 1 & 3 & & & $\mathrm{x}$ & $\mathrm{x}$ & $\mathrm{x}$ & 2 & & & & & $\mathrm{x}$ & & & 7 \\
\hline Spain & 1 & $\mathrm{x}$ & & $\mathrm{x}$ & $\mathrm{x}$ & $\mathrm{x}$ & $\mathrm{x}$ & 2 & $\mathrm{x}$ & & 3 & & $\mathrm{x}$ & & & 10 \\
\hline Sweden & 2 & $\mathrm{x}$ & & $\mathrm{x}$ & $\mathrm{x}$ & $\mathrm{x}$ & & 3 & & 1 & $\mathrm{x}$ & & $\mathrm{x}$ & $\mathrm{x}$ & & 10 \\
\hline Switzerland & 2 & $\mathrm{x}$ & & & $\mathrm{x}$ & $\mathrm{x}$ & $\mathrm{x}$ & 3 & & $\mathrm{x}$ & $\mathrm{x}$ & & $\mathrm{x}$ & & & 9 \\
\hline Turkey & 1 & $\mathrm{x}$ & & $\mathrm{x}$ & $\mathrm{x}$ & 2 & $\mathrm{x}$ & $\mathrm{x}$ & $\mathrm{x}$ & 3 & $\mathrm{x}$ & $\mathrm{x}$ & $\mathrm{x}$ & & Enbio & 13 \\
\hline UK & $\mathrm{x}$ & $\mathrm{x}$ & & & $\mathrm{x}$ & $\mathrm{x}$ & $\mathrm{x}$ & 2 & & & & & $\mathrm{x}$ & 1 & & 8 \\
\hline Total & 24 & 23 & 3 & 7 & 22 & 23 & 19 & 24 & 8 & 13 & 10 & 7 & 18 & 6 & & \\
\hline
\end{tabular}

global net income list $(\rho=0.822, p=0.000)$. Finally, there was a statistical correlation between the number of centres per nation and the overall ranking on the per capita income list $(\rho=0.466, p=0.016)$.

\section{Discussion}

The EABIP undertook this survey to assess the current practices of AS in adults within Europe, the birthplace of this technique. According to current geographical and political definitions, Europe represents a total of 51 countries; however, only 26 countries have a national delegate represented within the EABIP. Among these 26 countries, with a total population of 580 million, AS is performed in all but one country (Macedonia).

Of the remaining 25 countries, 3 of the 4 largest nations (in terms of population) have more than 30 centres practicing AS: Germany, the UK, and France. Based on the results of this survey, it appears that more than 200 centres perform AS in Germany. In addition, these 3 nations represent the highest ranked nations within Europe 
Table 3. Statistical analysis between GNI, PCI, and number of centres per country

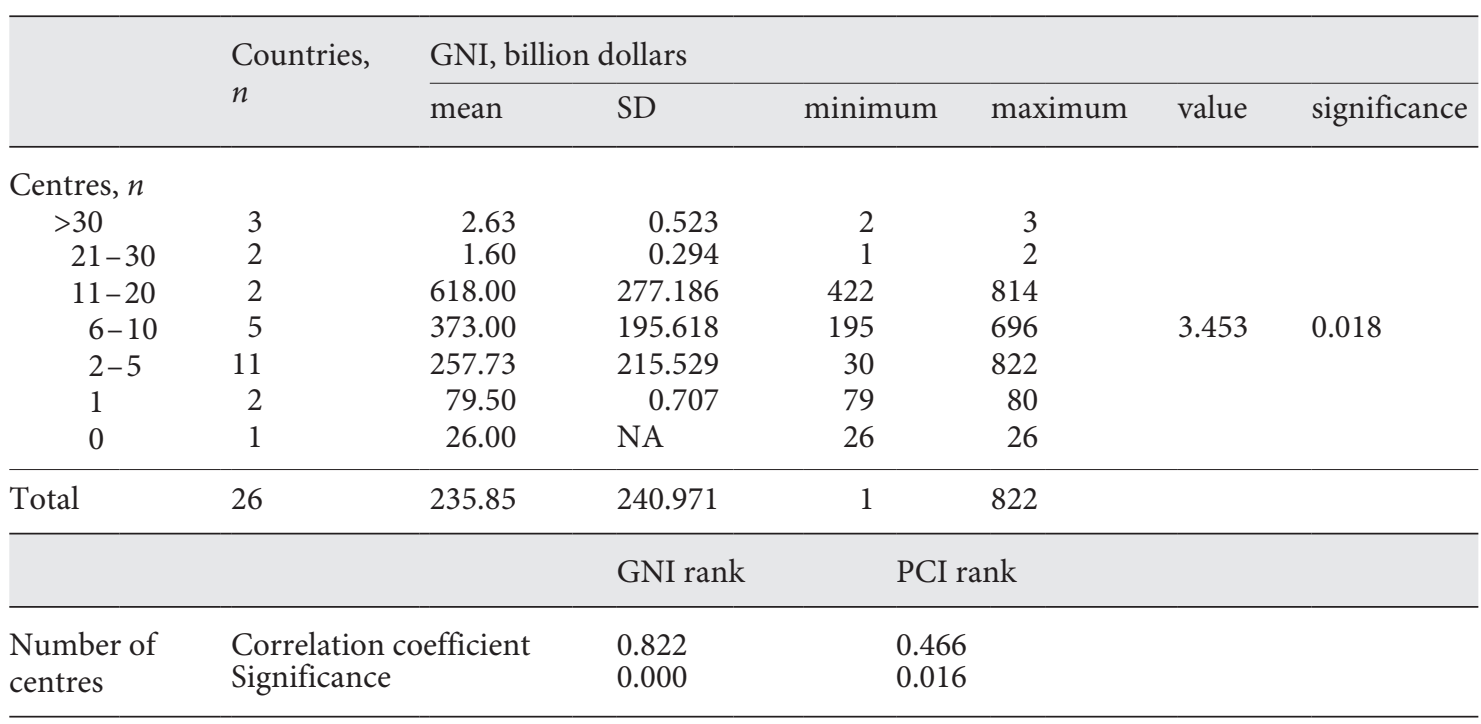

GNI, global net income; PCI, per capita income; SD, standard deviation; NA, not appicable.

in terms of gross national income. These results show that these countries have 1 AS centre for every 2.3 million inhabitants.

Turkey, which is the third largest country in Europe, based on population (6th in terms of gross national income, 26 th in terms of per capita income), has only $2-5$ centres performing AS. However, AS is a relatively new procedure available in Turkey and it is possible that training is still required to increase the number of centres offering the technique. The Turkish national delegate stated that:

In Turkey, stent placement should be standardized and we will begin a certificate program which lasts 6 months including theoretical and practical education with the Ministry of Health. Interventional Pulmonology is not a subspecialty in Turkey as it is in the rest of Europe. However, we think that education and interventions have to be strictly standardized to ensure a good and effective clinical approach.

The next two most populated countries, Italy (4th) and Spain (5th), have between 21 and 30 centres. This represents 1 centre for every 1.8-2.6 million inhabitants. These are followed by Poland and Belgium listed 7th and 10th, respectively, in terms of population. These countries have between 11 and 20 centres performing AS, equating to 1 centre for every 1.23-2.24 million inhabitants.

Four other countries, Austria, Finland, Portugal, and Switzerland, listed 15th, 19th, 12th, and 15th, respectively, in terms of population, have between 6 and 10 centres each (i.e., 1 centre for every $0.8-1.3$ million inhabitants).
Twelve countries, with a total population of close to 168 million, have between 2 and 5 centres performing AS. Amongst these countries, there is a large heterogeneity in terms of centres per population; for instance, Turkey has 1 centre for approximately 15 million inhabitants, while Estonia has 1 centre for less than 1 million people.

Finally, 2 countries, Croatia and Serbia, report 1 centre performing AS in the country. This represents 1 centre per 6.25 million inhabitants.

Therefore, in summary of the above results, this paper demonstrates that the most populated countries in Europe have more centres than the least populated nations. However, when the data is analysed per population, there is good homogeneity between all countries with roughly 1 centre for 1.3-2.2 million people, with the exception of Turkey, Croatia, and Serbia.

Since the earliest years of interventional pulmonology, AS has been performed by different specialists: pulmonologists, ENT surgeons, thoracic surgeons, and radiologists. For instance, J.F. Dumon, L. Freitag, and Marc Noppen are pulmonologists, while William Montgomery was an ENT surgeon. In addition, numerous thoracic surgeons have been trained in this technique. In many cases, this was a skill set learned by the thoracic surgeon to repair postsurgical anastomotic complications, but the skill was additionally used to manage central airway disease. Our survey demonstrated that AS is exclusively or predominantly performed by pulmonologists in 17 out of the reporting 26 countries and equally performed by both 
specialties in 3 nations. Furthermore, AS is primarily performed by thoracic surgeons in 3 countries (Estonia, Finland, and Poland). The national delegate from Finland explained this finding by stating that the procedure is only economically viable if performed as a surgical procedure.

Overall, it is difficult to explain the variation in terms of AS operator between the European countries. We suggest that each country should review their AS practices, both current and historical, as this may assist in explaining the differences in national practices. We can make the hypothesis that these variations are due to a number of factors that not only vary from country to country but also from unit to unit within a country, for example skill set/training of the operator, training in RB, accessibility to a dedicated unit, availability and ease of access to GA, tradition, and, most significantly, reimbursement patterns in each health care structure. However, despite these multiple factors, it does appear that AS remains within the domain of pulmonologists in the majority of European countries.

In all reporting European countries, AS is performed primarily within the public hospital sector. As per our previous analysis, it is unclear why this pattern exists, and indeed without a precise and exhaustive analysis of individual health services, which differ significantly from nation to nation within Europe, it is impossible to be certain of this result. However, we hypothesize that only largevolume private institutions can offer the procedure at a frequency high enough to make it financially viable. In addition, most AS services have developed in institutions with on-site thoracic surgery facilities; these are often not available in medium-sized private hospitals. In our opinion, the presence of a thoracic surgery department is mandatory for a safe AS service and, in return, interventional pulmonologists will be referred patients requiring stent placement after surgical interventions. In addition, our surgical colleagues are occasionally needed to assist in the care of patients developing complications after endoscopic procedures. In certain countries, current AS reimbursements are not rewarding enough for private structures to develop these techniques.

In the majority of European countries, AS is performed under GA, and this survey has shown that the procedure is performed exclusively under GA in 16 countries. Nine countries reported that AS can be performed under local anaesthesia. This is most likely explained by physician difficulty in accessing operating room facilities and anaesthetic cover. The lack of RB skills remains an important factor explaining why some centres still perform AS using flexible bronchoscopes [35]. For instance, in the $\mathrm{UK}$, pulmonologists do not have easy access to RB as it is generally performed by thoracic surgeons. The recommendations of the British Thoracic Society guidelines [36] state that "the majority of the published case series regarding outcomes and complications of stent deployment are for deployment by rigid bronchoscopy only. Flexible bronchoscopy is an alternative to rigid bronchoscopy to deploy metallic airway stents." Although NICE guidelines [37] state that all cancer centres need to provide access to AS, the subsequent British Thoracic Guidelines supported stenting under FB guidance. This is despite these guidelines clearly stating the significant benefits of RB over FB techniques. However, they completed the guideline by stating that most clinicians did not have adequate training or a skill set in RB and therefore flexible procedures were acceptable. The outcome of these statements is that pulmonologists in the UK continue to place metallic stents using a flexible bronchoscope with or without GA, while surgeons are capable of placing both metallic and silicone stents using RB. It is also important to recognize that $\mathrm{RB}$ is generally necessary to place stents in patients who have airway obstruction secondary to anything other than routine malignant tracheobronchial disease [37]. RB requires either a state-of-the-art bronchoscopy suite equipped to provide GA or an operating room. This scenario is rarely available to pulmonologists in the UK. In addition, few operators have adequate volume to demand a dedicated session in the operating room. As can be expected, and particularly at the early stage of service development, referred cases can be irregular and erratic, thus leading to uncertainty in procedure scheduling compared to more established and highervolume surgical procedures. Dedicating one or two halfday lists per week for procedures allows for more consistent scheduling, but it does not eliminate the issue of obtaining regular operating room time [38].

This survey demonstrates that RB is favoured in 20 countries and that $\mathrm{RB}$ and $\mathrm{FB}$ are equally utilized in 2 other nations. Only 2 countries favour FB. Physicians with adequate RB skills are probably the primary factor for deciding on the type of AS procedure and stent selection. The lack of RB training remains a significant factor, despite the recommendations of respiratory societies. The ACCP guidelines [39] state that "dedicated operators performing airway stenting should have extensive experience in flexible and rigid bronchoscopy and management of central airway lesions." To maintain competency, dedicated operators should perform at least 10 procedures per year. In order to make the best choice for the indi- 
vidual patient, the dedicated operator should be proficient in the placement of both flexible and silicone stents. The ATS and ERS statement [40] wrote: "Stent insertion should be reserved for bronchoscopists who have had ample experience with rigid/flexible bronchoscopy and endotracheal intubation. In order to maintain competence, 5-10 procedures per year should be performed."

In these two recommendations, the volume of the procedures is probably not enough to maintain competence, especially if a unit is utilizing multiple stent types. Our questionnaire has shown that there are 14 brands available in Europe. In addition, 3 countries have locally developed stents available. The survey has shown that 8 countries have more than 10 types of stents available for use, while 2 countries have less than 5 stents on the market. Surprisingly, Turkey, which has only $2-5$ centres performing AS, has 13 different stent types on the market. There is no doubt that companies have focused on this country as an emerging market for future sales.

The most widely available stents in Europe are the Dumon, Polyflex, T-Tube, Ultraflex, Dynamic, and Silmet stents. Not surprisingly, all of these stents are distributed by the two biggest and historically most active companies in this field: Novatech SA and Boston Scientific. Of the top 3 stents, Dumon (silicone stent) is available in 18 countries and Ultraflex (self-expandable nitinol stent) is available in 15 countries. These stents are clearly the market leaders. Other silicone stents such as the Polyflex and Noppen stents appear to have a limited market share, while the newer brands of fully covered metallic stents such as Aerstent (3rd rank), Silmet (4th rank), and Microtech stents (5th rank) may need more time to establish themselves in this area and ultimately challenge the monopoly enjoyed by the Dumon and Ultraflex stents.

The choice of a stent, as already stated, relies not on evidence-based medicine but primarily on the skills of the operators in both FB and RB, on stent availability, on overall commercial strategies, and on other, multiple subjective factors and expert opinions.

Unfortunately, the growth of AS may be limited by local and national reimbursement strategies rather than patient clinical benefit, which is obvious. Overall, 12 countries stated that the procedure of AS is financially viable. Within these countries, financial viability relies on a combination of factors: commercial stent price, favourable stent, and procedure reimbursement by local national institutions or private insurance companies to ensure that the overall financial position for the institution is favourable.

On the other hand, 10 national delegates stated that AS is not financially worthwhile in their jurisdiction. For in-

Current Practice of AS in the Adult

Population in Europe stance, in Bulgaria, the national delegate wrote that "Airway stenting is not reimbursed and patients have to pay for the procedure themselves (about 700 Euro for a silicone stent and 1,300 Euro for a metal stent). The National Health Insurance Fund pays about 450 euros for this interventional procedure. Therefore airway stenting is not a profit-earning activity for our institutions."

The delegate from Croatia stated that "the price for stent placement is less than the cost of the stent itself. By including the price of dilatation and other procedures performed before stent placement, we can reach an amount that is greater than the price of the stent."

In Hungary, the delegate reported that "stents are reimbursed on a case by case basis, strictly by the cost of the stent, without any further reimbursement. It means that it is not worth doing this kind of service." In Portugal, "there is no reimbursement for stents and every time we place a stent the cost comes out of the hospital's budget."

In Romania, AS is not financially viable "because the price of the stent is very high (between 500-1,000 Euro) comparing with the average income of people (200-300 Euro) and the price of the stent is not covered by health insurance. The National Health Insurance scheme does not pay for the interventional procedures and the reimbursement for one bronchoscopy is about 100-150 Euro, no matter how complex the procedure is (the same price for diagnostic and interventional procedures)."

The Serbian delegate stated that "our Medical Authorities do not reimburse stenting anymore so our procedure rate has decreased significantly."

There is very little published data regarding the economic value of AS. Lund et al. [38] wrote that, in the USA, considering the time necessary for performing advanced therapeutic bronchoscopy, the professional fees are not attractive. The net facility reimbursement largely depends on stent costs and airway stent placement is not reimbursed at competitive rates and may even lead to a net loss for the facility.

The practice management benefits of central airway therapy are probably best obtained by a multidisciplinary airway team within an established cancer centre structure. It is obvious that AS in a pulmonary practice requires expertise with other procedures and a substantial capital investment (e.g., for thermal ablation technology, bronchoscopes, and RB equipment).

The finances of stenting and interventional bronchoscopy differ greatly between a multidisciplinary disease management team and a physician in private practice. Most reimbursement schemes will pay for a single procedure irrespective of the complexity of the intervention. 
For example, if an interventional bronchoscopy procedure requires the destruction of a tumour followed by a bronchoplasty with stent placement in the bronchus, the reimbursement is substantially lower than that obtained if each procedure was performed individually.

The complexities of stenting require both $\mathrm{RB}$ and $\mathrm{FB}$ facilities and are dependent on the airway disease and stent type required. Unfortunately, the required skill sets, training, associated risks, and limited pool of technical competency in performing $\mathrm{RB}$ are not recognized.

Improved reimbursement for bronchoscopic stent placement is required. These are high-risk, complex procedures and are usually performed in patients with poor physiologic reserve and significant co-morbidities and associated poor performance status. However, current reimbursement is a significant deterrent to AS. Current facility reimbursement rules are a disincentive to developing outpatient procedures and the use of metallic stenting. Currently, it appears that the best business model is a hospital-funded or health system-funded regional centre of excellence using a cost-centre approach to evaluate the real return on the investment.
This survey was performed to assess the current status and practices of AS in Europe. There are, however, a number of limitations in the results. It was not possible to collect precise data with respect to the indications for AS or the total number of stents placed per centre and per country. In some countries (the UK, Poland, and Denmark), the national delegate was unable to provide accurate data on the most popular stents placed in their region. However, the merit of this collaborative work is to provide a snapshot of AS practice in the 26 European members of the EABIP.

It is impossible to draw accurate conclusions, guidelines, or recommendations on AS practice given the limitations of this work and given the heterogeneity in practice and economic variability within countries. The EABIP has no role in the strategic planning of the health services of each country; however, the association can support and develop AS within Europe by developing ongoing training programs and courses and ensuring that skills and knowledge are shared amongst centres to create a greater standardization of practices within the region.

\section{Appendix 1: Questionnaire}

Country:

Population of your country?

Is airway stenting performed in your country? Yes: No:

If yes, and to your knowledge:

1. How many centers in your country provide this technique?

\begin{tabular}{|l|l|}
\hline A: 1 & \\
\hline B: $2-5$ & \\
\hline C: $6-10$ & \\
\hline D: $11-20$ & \\
\hline E: $21-30$ & \\
\hline F: $>30$ & \\
\hline
\end{tabular}

2. Who performs this technique?

\begin{tabular}{|l|l|l|l|l|}
\hline & Never & Rarely & Often & Always \\
\hline Pulmonologists & & & & \\
\hline Thoracic surgeons & & & & \\
\hline ENT surgeons & & & & \\
\hline Radiologists & & & & \\
\hline
\end{tabular}

\section{In which institution?}

\begin{tabular}{|l|l|l|l|l|}
\hline Public hospital & Never & Rarely & Often & Always \\
\hline Private hospital & & & & \\
\hline
\end{tabular}


4. Is stenting performed under local or general anesthesia?

\begin{tabular}{|l|l|l|l|l|}
\hline Local anesthesia & Never & Rarely & Often & Always \\
\hline General anesthesia & & & & \\
\hline
\end{tabular}

5. Is stenting performed using flexible or rigid bronchoscopy?

\begin{tabular}{|l|l|l|l|l|}
\hline Flexible & Never & Rarely & Often & Always \\
\hline Rigid & & & & \\
\hline
\end{tabular}

6. Commercially available stents in your country? (please tick more than one if appropriate)

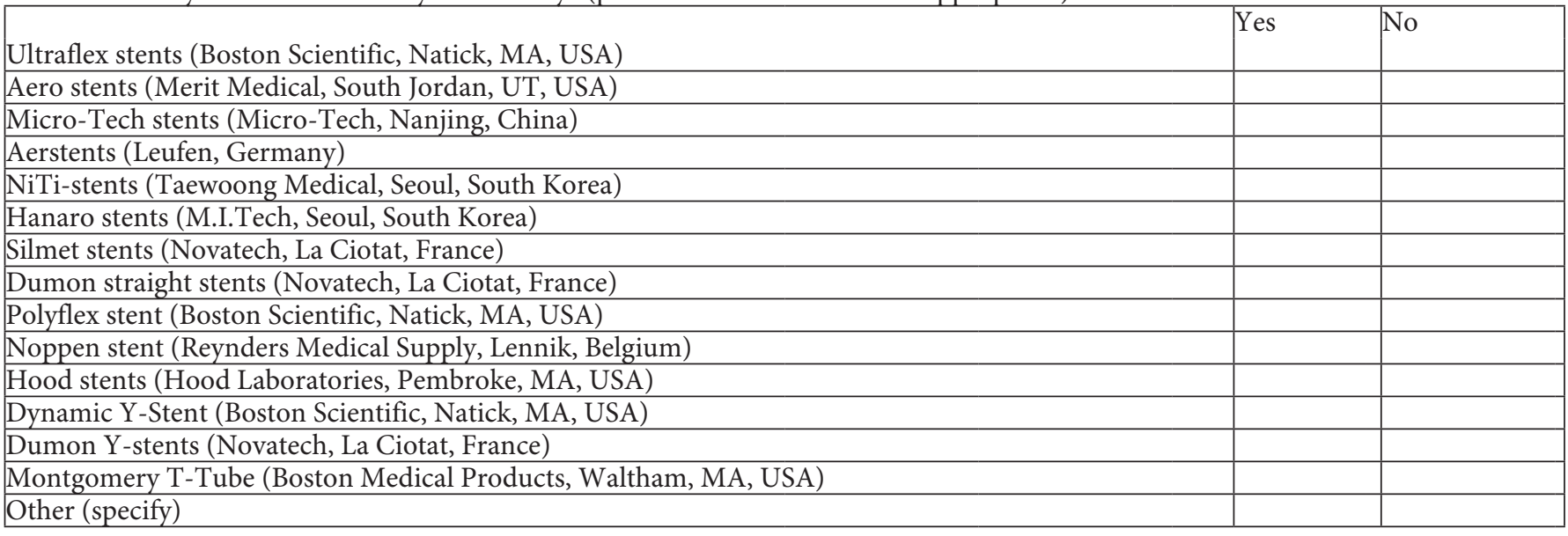

7. Among the commercially available stents in your country, which are the 3 most commonly placed (in decreasing order)?

8. Would you say that airway stent placement is economically worth in your country?

a. Yes

b. No

Why? (Free text to explain):

\section{References}

1 Wood De, Liu YH, Vallieres E, et al: Airway stenting for malignant and benign tracheobronchial stenosis. Ann Thorac Surg 2003;76: 167-174.

2 Freitag L: Airway stents; in Strausz J, Bolliger CT (eds): Interventional Pulmonology. European Respiratory Society, 2010, vol 48, 190217.

3 Trendelenburg F: Beiträge zu den Operationen an den Luftwegen. Langenbecks Arch Chir 1872;13:335.

4 Bond CJ: Note on the treatment of tracheal stenosis by a new T-shaped tracheostomy tube. Lancet 1891;1:539-540.

5 Brunings W, Albrecht W: Direkte Endoskopie der Luft- und Speisewege. Stuttgart, Ferdinand Enke, 1915, pp. 134-138.

6 Canfield N, Norton N: Bony stenosis of the larynx. Ann Otol Rhinol Laryngol 1949;58: 559-565.

Current Practice of AS in the Adult Population in Europe
7 Harkins WB: An endobronchial metallic prosthesis in the treatment of stenosis of the trachea. Ann Otol Rhinol Laryngol 1952;61: 663-675.

8 Montgomery WW: T-tube tracheal stent. Arch Otolaryngol 1965;82:320-321.

9 Andersen HC, Egknud P: Intratracheal tube treatment of stenosis of the trachea. Acta Otolaryngol 1966;(suppl 224):29+.

10 Neville WE, Hamouda F, Anderson J, et al: Replacement of the intrathoracic trachea and both stem bronchi with a molded silastic prosthesis. J Thorac Cardiovasc Surg 1972;63: 569-576.

11 Westaby S, Jackson JW, Pearson FG: A bifurcated silicone rubber stent for relief of tracheobronchial obstruction. J Thorac Cardiovasc Surg 1982;83:414-417.

12 Orlowski TM: Palliative intubation of the tracheobronchial tree. J Thorac Cardiovasc Surg 1987;94:343-348.
13 Canfield N, Norton N: Bony stenosis of the larynx. Ann Otol Rhinol Laryngol 1949;58: 559-565.

14 Harkins WB: An endobronchial metallic prosthesis in the treatment of stenosis of the trachea. Ann Otol Rhinol Laryngol 1952;61: 663-675.

15 Dumon JF: A dedicated tracheobronchial stent. Chest 1990;97:328-332. 36

16 Wassermann K, Koch A, Muller-Ehmsen J, et al: Clinical and laboratory evaluation of a thinwalled self-expanding tracheobronchial silicone stent: progress and pitfalls. J Thoracic Cardiovasc Surg 1997;114:527-523.

17 Noppen M, Dhaese J, Meysman M, et al: A new screw-thread tracheal endoprosthesis. J Bronchol 1996;3:22-26.

18 Freitag L, Tekolf E, Eiker R, et al: Theoretical and experimental basis for the development of a dynamic airway stent. Eur Respir J 1994; 7:2038-2045. 
19 Pagliero KM, Shepherd MP: Use of stainlesssteel wire coil prosthesis in treatment of anastomotic dehiscence after cervical tracheal resection. J Thorac Cardiovasc Surg 1974;67: 932-935.

20 Filler RM, Buck JR, Bahiric A: Treatment of segmental tracheomalacia and bronchomalacia by implantation of an airway splint. J Pediatr Surg 1982;17:597-603.

21 Goddard JM, Booker PD: The use of bronchial stents in the management of bronchomalacia. Anaesthesia 1987;42:534-535.

22 Simonds AK, Irving JD, Clarke SW, et al: Use of expandable metal stents in the treatment of bronchial obstruction. Thorax 1989;44:680681.

23 Varela A, Maynar M, Irving D, et al: Use of Gianturco self-expandable stents in the tracheobronchial tree. Ann Thorac Surg 1990; 49:806-809.

24 Mair EA, Parsons DS, Lally KP: Treatment of severe bronchomalacia with expanding endobronchial stents. Arch Otolaryngol Head Neck Surg 1990;116:1087-1090.

25 Spatenka J, Khaghani A, Irving JD, et al: Gianturco self-expanding metallic stents in treatment of tracheobronchial stenosis after single lung and heart transplantation. Eur J Cardiothorac Surg 1991;5:648-654.

26 Nashef SA, Dromer C, Velly JF, et al: Expanding wire stents in benign tracheobronchial disease: indications and complications. Ann Thorac Surg 1992;54:937-940.
27 Do YS, Song HY, Lee BH, et al: Esophagorespiratory fistula associated with esophageal cancer: treatment with a Gianturco stent tube. Radiology 1993;187:673-677.

28 Rousseau H, Dahan M, Lauque D: Self-expandable prostheses in the tracheobronchial tree. Radiology 1993;188:199-203.

29 Dunne JA, Sabanathan S: Use of metallic stents in relapsing polychondritis. Chest 1994; 105:864-867.

30 Nakamura T, Shimitzu Y, Ito Y, et al: A new thermal shape memory Ti-Ni alloy stent covered with silicone. ASAIO J 1992;38:347-350.

31 Gildea TR, Downie G, Eapen G, et al: A prospective multicenter trial of a self-expanding stent in malignant airway obstruction. J Bronchol 2008; 15:221-224.

32 Dooms C, De Keukeleire T, Janssens A, et al: Performance of fully covered self-expanding metallic stents in benign airway strictures. Respiration 2009;77:420-426.

33 Dutau H, Musani AI, Plojoux J, Laroumagne S, Astoul P: The use of self-expandable metallic stents in the airways in the adult population. Expert Rev Respir Med 2014;8:179-190.

34 Dutau H, Toublanc B, Lamb C, et al: Use of the Dumon Y-stent in the management of malignant diseases involving the carina: a retrospective review of 86 patients. Chest 2004; 126:951-958.
35 Dutau H: Airway stenting for benign tracheal stenosis: what's really behind the choice of the stent? Eur J Cardiothorac Surg 2011;40:924925.

36 Du Rand IA, Barber PV, Goldring J, Lewis RA, Mandal S, Munavvar M, Rintoul RC, Shah PL, Singh S, Slade MG, Woolley A; British Thoracic Society Interventional Bronchoscopy Guideline Group: British Thoracic Society guideline for advanced diagnostic and therapeutic flexible bronchoscopy in adults. Thorax 2011;66(suppl 3):iii1-iii21.

37 NICE guidelines on the diagnosis and treatment of lung cancer. 2011. https://www.nice. org.uk/guidance/cg121/evidence/full-guideline-181636957.

38 Lund ME, Garland R, Ernst A: Airway stenting: applications and practice management considerations. Chest 2007;131:579-587.

39 Ernst A, Silvestri GA, Johnstone D; American College of Chest Physicians: Interventional pulmonary procedures: guidelines from the American College of Chest Physicians. Chest 2003;123:1693-1717.

40 Bolliger CT, Mathur PN, Beamis JF, Becker HD, Cavaliere S, Colt H, Diaz-Jimenez JP, Dumon JF, Edell E, Kovitz KL, Macha HN, Mehta AC, Marel M, Noppen M, Strausz J, Sutedja TG; European Respiratory Society/ American Thoracic Society: ERS/ATS statement on interventional pulmonology. European Respiratory Society/American Thoracic Society. Eur Respir J 2002;19:356-373. 